\title{
openheart Percutaneous left atrial appendage occlusion for stroke prevention in atrial fibrillation: an update
}

\author{
O De Backer, S Arnous, N Ihlemann, N Vejlstrup, E Jørgensen, S Pehrson, \\ T D W Krieger, P Meier, L Søndergaard, O W Franzen
}

To cite: De Backer 0 , Arnous S, Ihlemann N, et al. Percutaneous left atrial appendage occlusion for stroke prevention in atrial fibrillation: an update. Open Heart 2014;1:e000020. doi:10.1136/openhrt-2013000020

Received 13 December 2013 Revised 13 February 2014 Accepted 29 April 2014
CrossMark

Department of Cardiology, Rigshospitalet, Copenhagen $\emptyset$, Denmark

Correspondence to Dr 0 De Backer; ole.debacker@gmail.com

\section{ABSTRACT}

Atrial fibrillation (AF) is the most common sustained cardiac arrhythmia encountered in clinical practice. One of its most devastating complications is the development of thromboembolism leading to fatal or disabling stroke. Oral anticoagulation (OAC, warfarin) is the standard treatment for stroke prevention in patients with AF with an increased stroke risk. However, there are several obstacles to long-term OAC therapy, including the risk of serious bleeding, several drugdrug interactions and the need for frequent blood testing. Although newer oral anticoagulants have been developed, these drugs also face issues of major bleeding and non-compliance. Therefore, alternative treatment options for stroke prevention in patients with AF with a high stroke risk are needed. Percutaneous left atrial appendage (LAA) occlusion is an evolving therapy, which should be taken into consideration in those patients with non-valvular AF with a high stroke risk and contraindications for OAC. This article aims to discuss the rationale for LAA closure, the available LAA occlusion devices and their clinical evidence until now. Moreover, we discuss the importance of proper patient selection, the role of various imaging techniques and the need for a more tailored postprocedural antithrombotic therapy.

\section{INTRODUCTION}

Atrial fibrillation (AF) is the most common sustained cardiac arrhythmia, affecting 3-5\% of the population aged $65-75$ years, and increasing to $>8 \%$ of those older than 80 years. $^{1-4}$ It is associated with substantial mortality and morbidity, particularly due to fatal or disabling stroke. The risk of ischaemic stroke in patients with non-valvular AF (NVAF) is $3-5 \% /$ year, which is a fivefold increase compared with the unaffected population (figure 1). Overall, AF accounts for $15-20 \%$ of strokes in the general population and for up to $30 \%$ in patients over the age of 80 years. $^{5-9}$

For prevention of this complication, oral anticoagulation (OAC) is the standard treatment in patients with AF with a $\mathrm{CHA}_{(2)} \mathrm{DS}_{2^{-}}(\mathrm{VASc})$ stroke risk score $\geq 1$. $^{10}$ This anticoagulant therapy has been proven to effectively prevent thromboembolic strokes, but the increased risk of serious bleeding prevents many patients from taking this therapy. $^{11} 12$ Therefore, alternative treatment options for stroke prevention-without increasing the risk of bleeding-in patients with $\mathrm{AF}$ with increased stroke risk are needed.

Percutaneous left atrial appendage (LAA) occlusion is an evolving therapy, which should be taken into consideration in those patients with AF with a high stroke risk and contraindications for OAC. ${ }^{10} 13$ As a relatively new invasive procedure, it still needs to be demonstrated that its efficacy in preventing stroke outweighs the possible complications it may cause. This review aims to discuss the rationale for LAA closure, the available LAA occlusion devices and their clinical evidence until now. Moreover, we discuss the importance of proper patient selection, the role of various imaging techniques and the need for a more tailored postprocedural antithrombotic therapy.

\section{Treatment options for stroke prevention}

Multiple, large randomised controlled trials (RCTs) have clearly established the efficacy of OAC therapy in lowering the risk of stroke and death in patients with AF with a high stroke risk. ${ }^{10}$ However, there are several obstacles to long-term OAC therapy. The biggest risk is major bleeding, which has an incidence of $2-4 \% /$ year $^{14-16}$ and can be even higher if predisposing factors are present. In addition, these drugs have a small therapeutic window, several food and drug interactions and require frequent blood testing, which makes this therapy inconvenient to many patients. As a consequence, OACs are currently not prescribed and/or rigorously taken in up to $50 \%$ of patients with AF who are at high risk 


\begin{tabular}{|c|c|c|c|}
\hline $\mathrm{CHA}_{(2)} \mathbf{D S}_{\mathbf{2}^{-}}$(VASc) & Score & HAS-BLED & Score \\
\hline $\mathrm{CHF}$ & 1 & Hypertension & 1 \\
\hline Hypertension & 1 & Abnormal renal or & 1 or 2 \\
\hline Age $>75$ & 1 & liver function & \\
\hline Diabetes & 1 & Stroke & 1 \\
\hline Stroke/TIA & 2 & Bleeding & 1 \\
\hline Vascular disease & 1 & Labile INR & 1 \\
\hline Age $65-74$ & 1 & Elderly (> 65) & 1 \\
\hline Sex female & 1 & Drugs or alcohol & 1 or 2 \\
\hline Maximum & (9) points & Maximum & 9 points \\
\hline
\end{tabular}

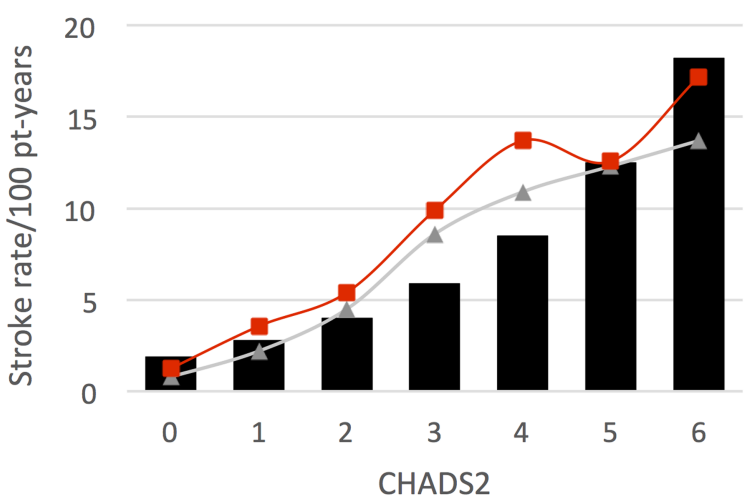

$\simeq$ Gage (2001) —-Gage (2004) —-Olesen (2011)

Figure 1 The $\mathrm{CHA}_{(2)} \mathrm{DS}_{2}$-(VASc) stroke risk and HAS-BLED bleeding risk index are calculated by totalling the scores for each risk factor present. ${ }^{68-71}$ The lower graph shows the expected stroke rate /100 patient (pt)-years, stratified by $\mathrm{CHADS}_{2}$ score in patients with AF not taking warfarin. Gage (2001): adjusted stroke rates/100 pt-years, assuming that aspirin was not taken ${ }^{68}$; Gage (2004): stroke rates/100 pt-years of aspirin ${ }^{69}$; Olesen (2011): event rates of hospital admission and death due to thromboembolism in patients with $\mathrm{AF}$ not taking warfarin. ${ }^{70} \mathrm{AF}$, atrial fibrillation; $\mathrm{CHF}$, congestive heart failure; TIA, transient ischaemic attack; INR, international normalised ratio.

for thromboembolic events. ${ }^{11}$ There has been a large hope that the new oral anticoagulants (NOACs) would overcome these disadvantages; however, these drugs still face issues of major bleeding and non-compliance (table 1) and have been reported to have side effects like gastrointestinal intolerance. ${ }^{14-16}$

An appealing way to avoid the need for OAC therapy could be complete eradication of AF. However, so far, none of the strategies trying to control and/or eradicate $\mathrm{AF}$ - either by medical rhythm control or radiofrequency catheter ablation (RFA) - have been proven to eliminate the indication for long-term OAC therapy. Although a recent study suggests that patients who undergo RFA may have a lower risk of stroke than patients with $\mathrm{AF}$ who do not undergo RFA, ${ }^{17}$ the guidelines (so far) do not recommend discontinuation of OAC after AF ablation. ${ }^{10} 18$

\section{Rationale for LAA occlusion}

The rationale behind LAA occlusion has been derived from anatomic and echocardiographic findings identifying the LAA as the primary site of thrombus formation in patients with NVAF. In a review of 23 studies in which the LAA was examined by autopsy, direct intraoperative inspection or transoesophageal echocardiography (TEE), an intracardiac thrombus, was identified in $10-15 \%$ of cases of valvular $\mathrm{AF}$ and $\mathrm{NVAF}$-however, the anticoagulation status of these patients was not reported. Sixty per cent of atrial thrombi in valvular AF were found in the LAA, whereas in NVAF $>90 \%$ of thrombi were located in the LAA. ${ }^{19}$ Thus, with the LAA found to be the dominant source of thrombus in patients with NVAF, LAA closure (or exclusion) provides an appealing option for stroke prevention. ${ }^{19-21}$ Undoubtedly, in patients with AF with comorbidities, embolic strokes can also develop from non-cardiac origins such as atheromatous plaque in the thoracic aorta or carotid arteries. ${ }^{20}{ }^{22}$ Nevertheless, for patients with NVAF with contraindication(s) to OAC, the rationale for LAA occlusion is that this intervention reduces the risk of AF-induced stroke in such a range that it outweighs the possible risk on procedural complications. Whether this hypothesis applies to the different closure devices needs to be proven in future clinical trials. Consequently, the European Society of Cardiology (ESC) guidelines for the management of AF (2012) recommend that LAA closure may be considered in patients with a high stroke risk and contraindications for long-term OAC administration (Class IIb, level of evidence B). ${ }^{10}$

\section{Patient selection}

Percutaneous LAA occlusion offers an alternative to physicians who are facing a complicated risk-benefit analysis in patients with NVAF who should receive OAC therapy based on a high stroke risk score, but who also have a high bleeding risk. Theoretically, all patients with NVAF with increased stroke risk and contraindication(s) to OAC are possible candidates for LAA closure-patients who have no contraindication for OAC therapy should have LAA occlusion only in exceptional cases. ${ }^{13}$ 23-25

In clinical practice, patients with NVAF with a high stroke $\left(\mathrm{CHADS}_{2}\right)$ and bleeding (HAS-BLED) risk score are considered the most suitable candidates for this procedure. Recent data suggest that the higher the stroke risk of the individual patient, the larger the 'net clinical benefit' of LAA closure in comparison to OAC therapy. ${ }^{26}$ However, patients with a high risk for thromboembolismfor example, left ventricular (LV) dysfunction or prior stroke-have also been reported to be at a higher risk of thrombus formation in the LA cavity (and not in the LAA). ${ }^{27}$ Therefore, an assessment that considers the combined risk of stroke, thromboembolism, bleeding and other adverse events may be the best way to select patients most suitable for LAA closure (boxes 1 and 2).

Besides clinically identifying the most suitable patients with NVAF for LAA occlusion, it is also important to assess the technical feasibility of percutaneous LAA 
Table 1 Comparison of some clinical data from the PROTECT AF versus new oral anticoagulant trials *

\begin{tabular}{|c|c|c|c|c|c|}
\hline & $\begin{array}{l}\text { PROTECT AF } 55 \\
\text { LAA closure }\end{array}$ & $\begin{array}{l}\text { PROTECT AF }{ }^{55} \\
\text { warfarin }\end{array}$ & $\begin{array}{l}\text { Dabigatran }{ }^{14} \\
\text { (RELY) }\end{array}$ & $\begin{array}{l}\text { Rivaroxaban }{ }^{15} \\
\text { (ROCKET AF) }\end{array}$ & $\begin{array}{l}\text { Apixaban }^{16} \\
\text { (ARISTOTLE) }\end{array}$ \\
\hline Age, years & 71.7 & 72.7 & 71.5 & 73 & 70 \\
\hline $\mathrm{CHADS}_{2}$ & 2.2 & 2.3 & 2.1 & 3.5 & 2.1 \\
\hline $\mathrm{CHADS}_{2}>2(\%)$ & 52.9 & 57.6 & 32.7 & 87 & 30.2 \\
\hline Major or minor bleeding (\%) & - & - & 16.4 & 14.9 & 18.1 \\
\hline Major bleeding (\%) & 3.5 & 4.1 & 3.1 & 3.6 & 2.1 \\
\hline Stroke/systemic embolism (\%) & 2.3 & 2.7 & 1.1 & 1.7 & 1.3 \\
\hline Treatment abandoned at $>1$ year $(\%)$ & - & $16-34$ & 21 & 24 & - \\
\hline
\end{tabular}

closure in every single patient by means of a preprocedural TEE and/or CT imaging. Some specific aspects of the LAA should be assessed, as this may influence device/size selection and implantation success. Importantly, a thrombus in the LAA is regarded as a contraindication for device implantation-in these cases, patients should take preprocedural OAC therapy until the thrombus resolves. ${ }^{1328}$

\section{LAA anatomy}

The LAA has a highly variable anatomical structure and may be difficult to describe-however, it is important to correctly evaluate the LAA anatomy in order to optimise procedural success. The best way to determine the configuration and orientation of the LAA lobes is by CT and/or angiography; the LAA orifice and neck can also readily be examined by TEE. $^{29}$

Box 1 Possible indications for percutaneous LAA closure

Patients with $\mathrm{AF}$ at high stroke risk with

- High risk (or recurrence) of bleeding under (N)OAC due to

- Uncontrolled, severe hypertension

- Coagulopathies-low platelet counts, myelodysplastic syndrome (MDS)

- Inherited bleeding disorder-Von Willebrand disease, haemophilia

- Severe hepatic or renal dysfunction-eg, alcoholic liver cirrhosis

- Vascular disease or malformations- eg, intestinal angiodysplasia, Osler-Weber-Rendu previous intracerebral haemorrhage, cerebral microbleeds ( amyloid angiopathy), retinal vasculopathy

- Insufficiently treatable Gl disease with bleeding-eg, neoplastic disease, intestinal angiodysplasia

- Recurrent nephrolithiasis

- High probability of frequent and/or severe traumas-eg, epilepsy, in the elderly

- Ischaemic stroke despite well-controlled OAC therapy

- High probability of therapeutic non-compliance to (N)OAC

- Intolerance to (N)OAC drugs-Gl intolerance, severe liver/ kidney dysfunction, drug interactions

- Other contraindications for (N)OAC

$A F$, atrial fibrillation; GI, gastrointestinal; LAA, left atrial appendage; (N)OAC, (new) oral anticoagulants.
Most often, the LAAs are classified into four morphological groups: (1) chicken wing: an LAA with an obvious bend in the proximal part of the dominant lobe; (2) windsock: an LAA with a main lobe of sufficient length $(>4 \mathrm{~cm})$ as the primary structure; (3) cauliflower: an LAA that has limited overall length $(<4 \mathrm{~cm})$ without any forked lobes; (4) cactus: a dominant central lobe with secondary lobes extending from the central lobe. ${ }^{30}$ The frequency of the different morphologies varies in the different studies, which may be either an expression of the difficulty to classify the individual morphology or a consequence of different patient populations and/or definitions in the studies (figure 2)..$^{30} 31$

Recent data suggest that the 'chicken wing' morphology may be associated with a lower stroke risk ${ }^{32}$-in some cases, this morphology is a procedural challenge and a modified implantation technique may be preferred (figure 3). ${ }^{33} 34$ In contrast, the 'cauliflower' morphology as well as a smaller LAA orifice, larger neck dimension and extensive LAA trabeculation are associated with a higher stroke risk, as these factors potentially cause stasis and consequently thrombus formation in the LAA. ${ }^{35-37}$

From an interventional perspective, understanding the different configurations of the LAA ostium and neck is vital, as the occluder is anchored at the neck and must cover the ostium. A recent paper described three different morphologies of the LAA ostium and neck: (1) horn shaped: LAA ostium wider than the neck, (2) parallel tube: an ostium and neck that are similar in dimension and (3) and angel wing: a neck with larger dimensions

Box 2 Contraindications for percutaneous LAA closure

Low risk for stroke $\mathrm{CHA}_{(2)} \mathrm{DS}_{2}-(\mathrm{VASc})=0$

- Valvular heart disease (eg, mitral stenosis)

- Other indications for long-term or lifelong OAC-mechanical prosthetic valve, pulmonary embolism and deep vein thrombosis, thrombi in the left atrium or ventricle

- Contraindications for transseptal catheterisation-left atria thrombus or tumour, active infection, uncooperative patient, (presence of ASD/PFO closure device)

ASD, atrial septal defect; LAA, left atrial appendage; OAC, oral anticoagulants; PFO, patent foramen ovale. 

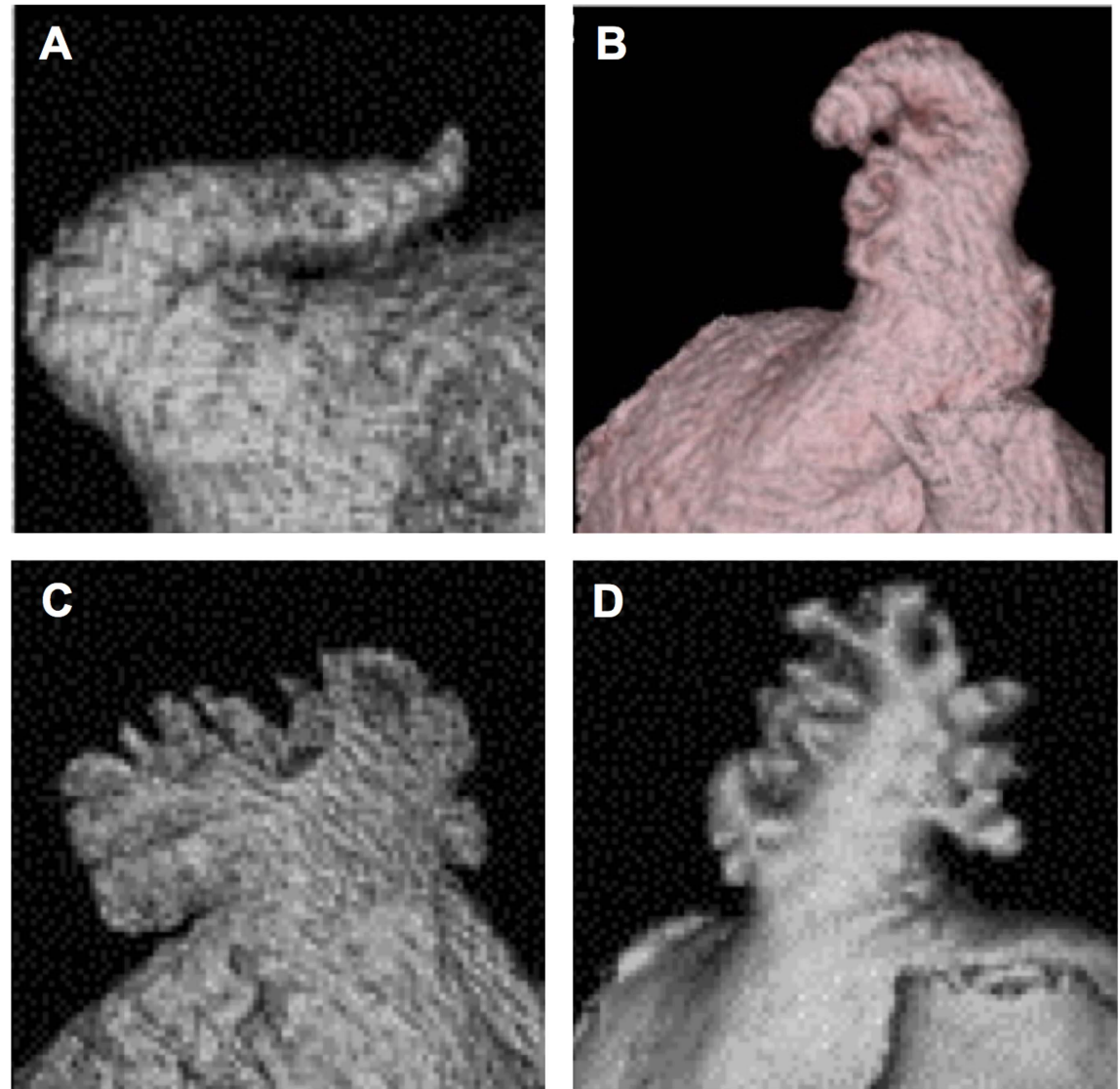

Figure 2 General morphology classification of left atrial appendage (LAA) as determined by cardiac CT. LAA can be classified into four types: (A) chicken wing type-with a short neck and an obvious bend, (B) windsock type, (C) cauliflower type and (D) cactus type. Images reproduced with permission from Wang et al. ${ }^{30}$
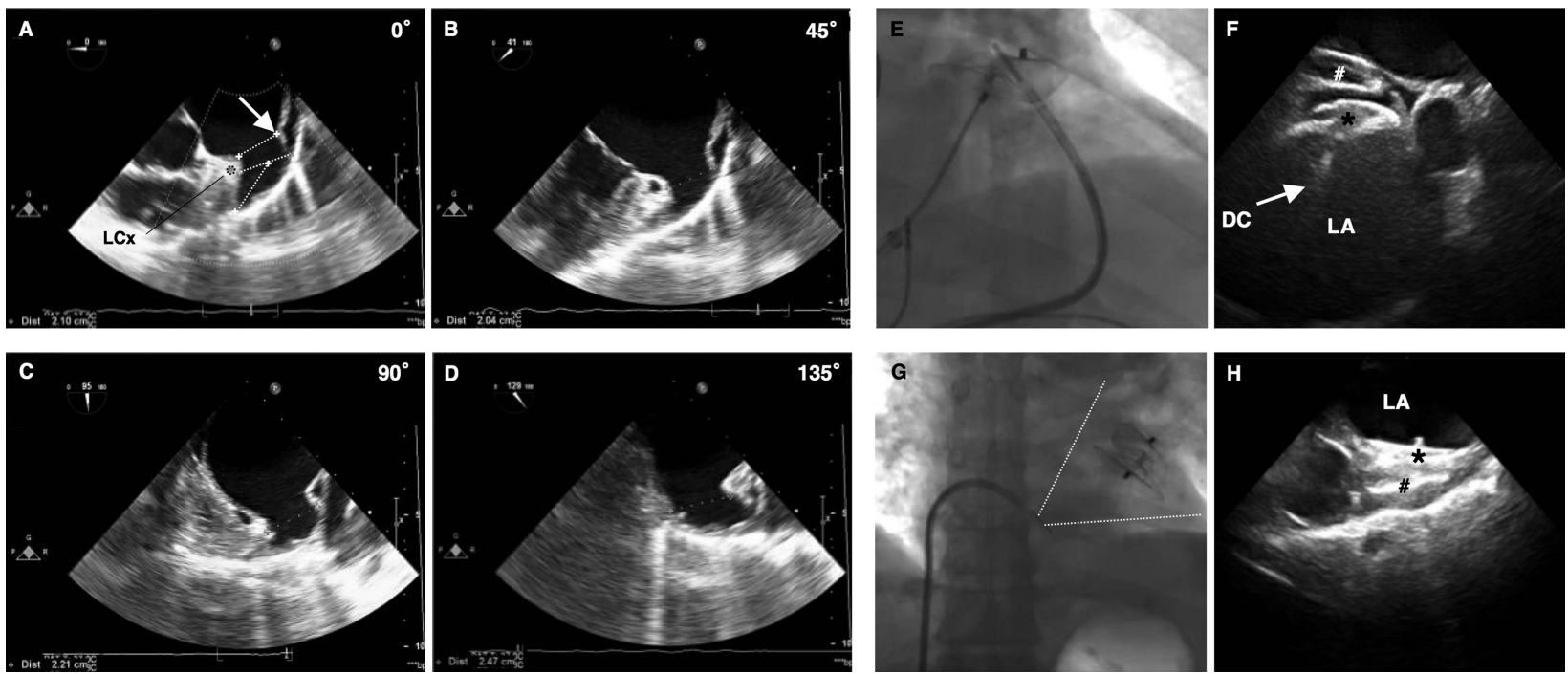

Figure 3 (A-D) Preprocedural transoesophageal echocardiography (TEE) imaging-left atrial appendage (LAA) anatomy and dimensions should be studied with the transducer array rotated through $0^{\circ}, 45^{\circ}, 90^{\circ}$ and $135^{\circ}$. (A) Shows in which manner the LAA ostium, LAA neck width (orifice width or 'landing zone') and LAA depth should be measured. The LAA neck width is typically measured in a plane from the $L C x$ coronary artery to a point $10 \mathrm{~mm}$ distal to the limbus (white arrow) of the left superior pulmonary vein (LSPV). In this case, we measured a neck width of 21-25 mm-which led to the choice of a $28 \mathrm{~mm}$ Amplatzer cardiac plug (ACP) device (because of oversizing with 3 to $5 \mathrm{~mm}$ ). The risk of undersizing is device embolisation; the risk of oversizing is compression on the LCx and/or LSPV, as well as LAA perforation and device embolisation. (E-H) Use of ICE to guide implantation of a LAA closure device. ICE imaging is optimal with the ICE probe in (E) the left pulmonary artery as well as $(G)$ with the transducer at the ostium of the coronary sinus. The ICE images were used to guide $(F)$ the delivery and $(H)$ proper deployment of the ACP device inside the LAA. DC, delivery cable; *disk of the ACP device; \# lobe of the ACP device. 
than the LAA ostium. These various LAA configurations can influence device/size selection and implantation success. The risk of device dislodgement is believed to be highest in patients with a horn-shaped configuration of the LAA. In these patients, choosing a device large enough to cover the ostium and yet maintain the optimal degree of oversizing in the 'landing zone' to secure anchorage can be a challenge. Moreover, other aspects such as the amount of trabeculation of the 'landing zone' and the depth of the LAA (especially important if using the WATCHMAN device) need to be assessed to ensure that the optimal device is chosen. ${ }^{29}$

\section{Imaging of the LAA}

TEE is an essential tool at all stages of a percutaneous LAA occlusion procedure: (1) preprocedural TEE is used to screen suitable candidates and to define LAA morphology and dimensions; (2) periprocedural TEE has a major role in guiding delivery and deployment of the device and for assessing procedural complications; and (3) postprocedural TEE is important in the surveillance and monitoring of long-term outcome. ${ }^{38-40}$

As stated above, an extensive preprocedural TEE examination should be performed in order to fully explore the LAA anatomy and to exclude a thrombus in

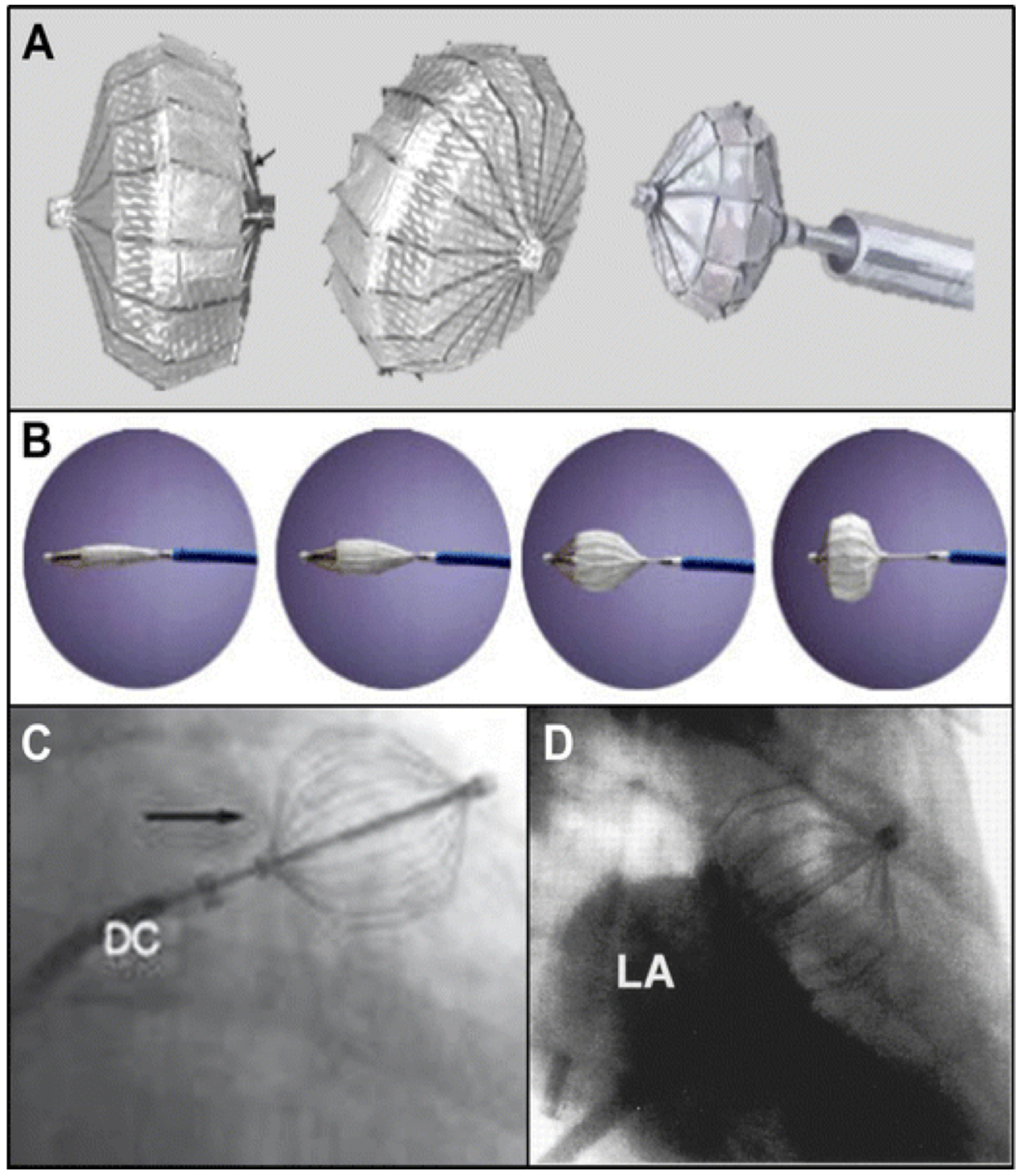

Figure 4 PLAATO device. (A) The PLAATO (Percutaneous Left Atrial Appendage Transcatheter Occlusion) system was the first device specifically developed for left atrial appendage (LAA) occlusion. It consisted of a self-expanding nitinol cage with three anchors on each strut and was covered with a non-thrombogenic PTFE membrane. The anchoring barbs provided the stability; the PTFE membrane prevented mobilisation of thrombi from the LAA and promoted healing. The device diameter ranged between 15 and $32 \mathrm{~mm}$ and was normally selected $20-40 \%$ larger than the diameter of the LAA ostium. The device is no longer available for clinical use after withdrawal from the market in 2006. (B) Shows-from left to right-a fully collapsed, partially expanded and fully expanded device advanced through a 12-Fr transseptal delivery sheath. (C, D) Illustrate a fluoroscopic right anterior oblique view in a patient, exhibiting the deployed PLAATO device (C) and in the setting of an LA angiogram (D) depicting proper LAA occlusion. Images reproduced with permission from Aryana et al. ${ }^{47}$ 
the LA(A). Important aspects to assess are the shape and size of the ostium, the width of the 'landing zone' (ie, area within the LAA where the device will be positioned), the length of the LAA and-if possible-the number, shape and location of the lobes (figure 3). ${ }^{38}$ In case of a large LAA neck width $(>26 \mathrm{~mm})$ or complicated LAA anatomy, additional preprocedural imaging with CT/MRI should be considered. This is because all devices have a certain upper limit in size (see figures 4 and 5), and a good preprocedural preparation can prevent the need for interrupting LAA closure procedures after induction of general anaesthesia. ${ }^{30} 41-43$ Finally, it is important to mention that the LAA size is dependent on the LA pressure ('loading status') as well as on the presence of sinus rhythm or AF. Therefore, some operators suggest measuring LAA dimensions
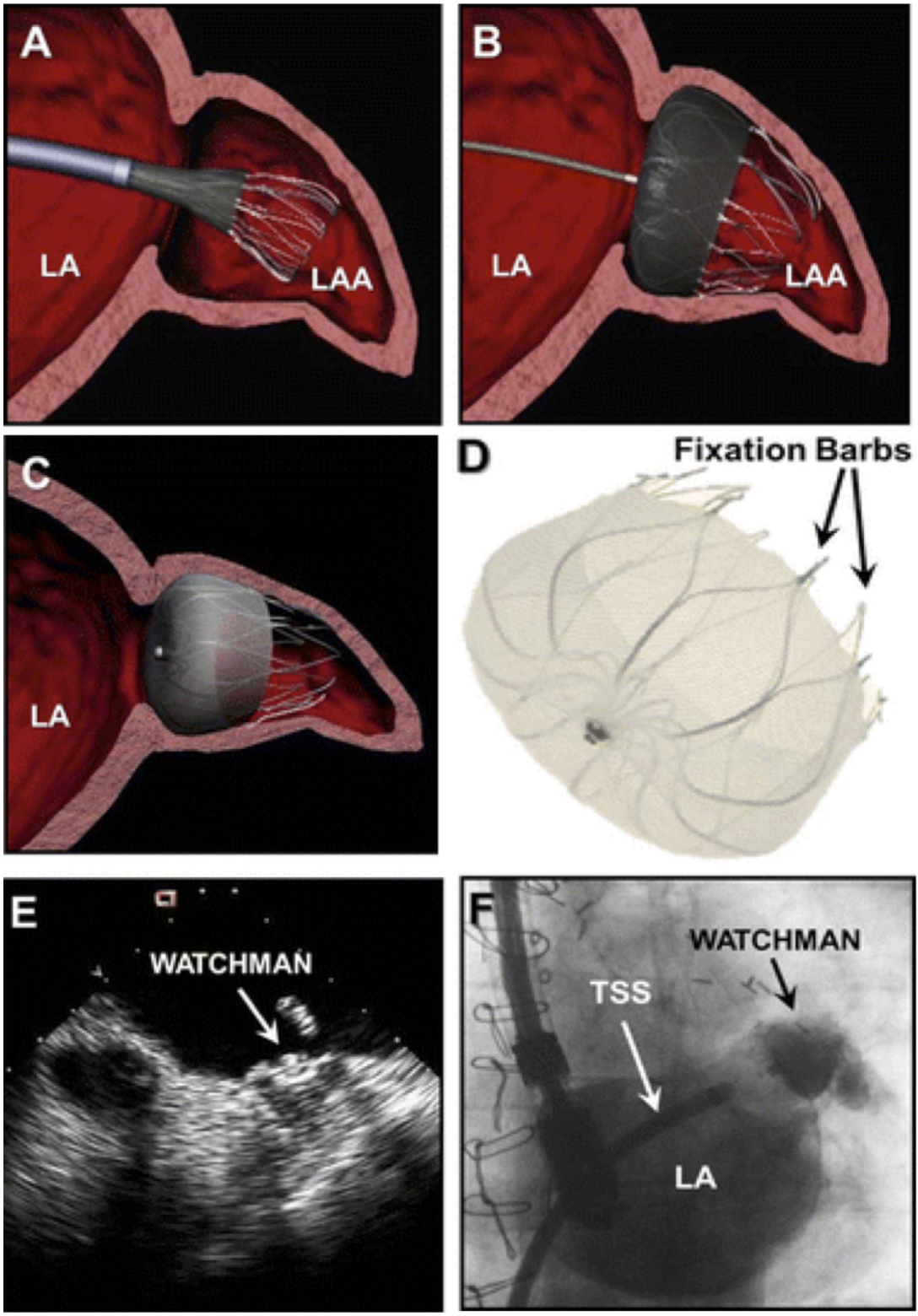

Figure 5 WATCHMAN device. (A-C) Show the delivery $(A)$, deployment $(B)$, and release $(C)$ of the WATCHMAN device through a 12-Fr transseptal delivery sheath. (D) Shows a close-up view of the WATCHMAN device-consisting of a self-expanding nitinol frame covered with a porous filtering PET membrane. The stability of the device is secured by fixation barbs located circumferentially; the PET membrane acts as a filter preventing the outflow of the thrombi and promotes endothelialisation. The device is available in five different sizes ranging from 21 to $33 \mathrm{~mm}$, and is normally selected $10-20 \%$ larger than the left atrial appendage (LAA) diameter to ensure stable device positioning. The device can be recaptured and withdrawn in case of suboptimal fixation. The WATCMAN device received CE-mark approval in 2005 and is currently used in clinical practice. (E) Shows a transoesophageal echocardiography image of an occluded LAA following deployment of a WATCHMAN device - the delivery cable is still connected to the device. (F) Shows a cine image of an LA angiogram demonstrating a WATCHMAN device properly deployed inside the LAA (black arrow). TSS, transseptal sheath. Images reproduced with permission from Aryana et al. ${ }^{47}$ 

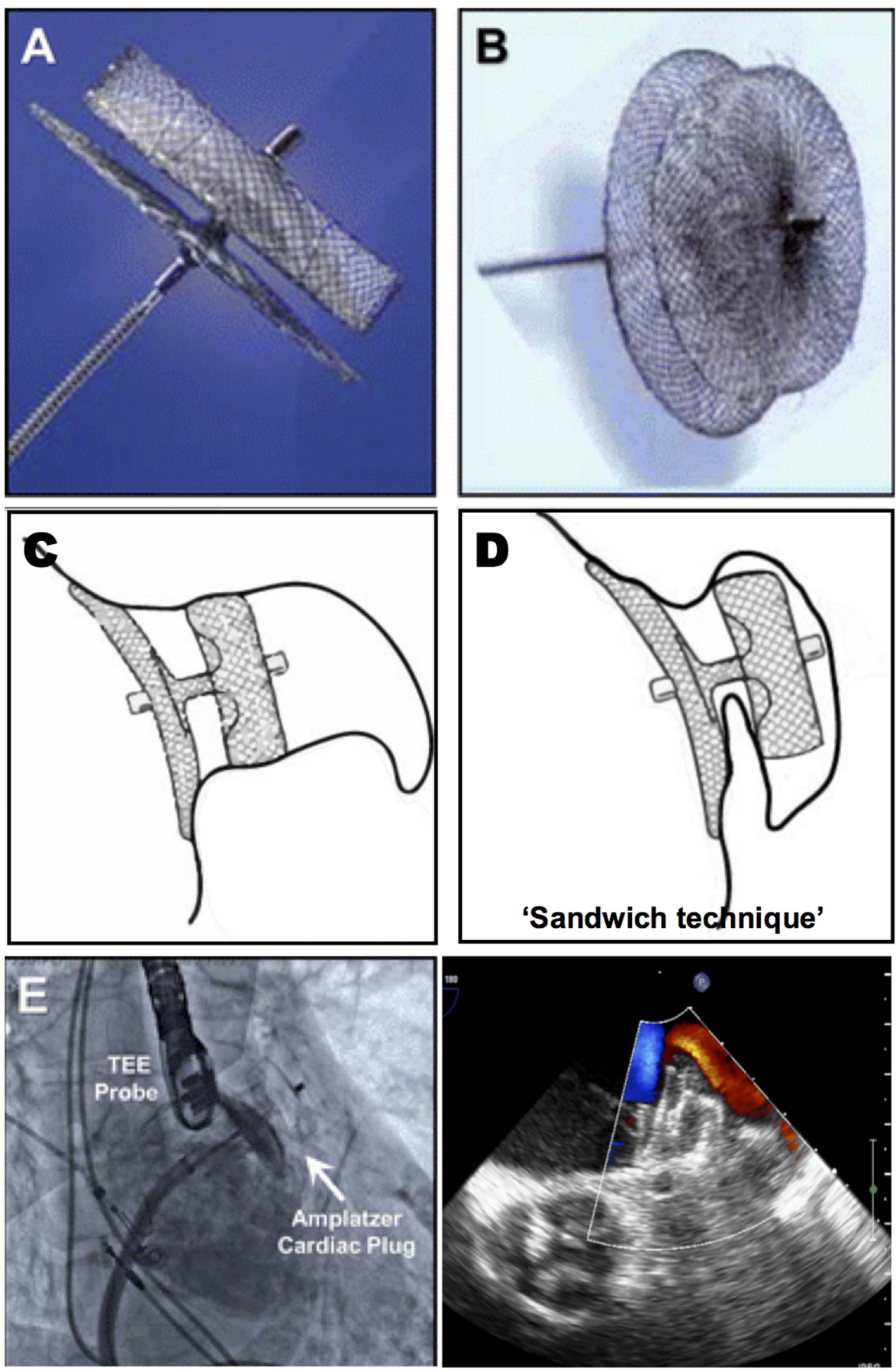

Figure 6 (A-B) the ACP device consists of a lobe and a disk connected by a short, flexible waist. Both the lobe and disk are constructed from a nitinol mesh covered with a polyester patch. The lobe is implanted within the neck of the LAA (the so-called 'landing zone'), and achieves device stabilization and retention by means of a number of stabilization wires. The delivery system is 9-13Fr depending on the size of the device. The lobe size ranges from 16-30 mm and the disk from 20-36 mm; the size of the lobe should be chosen 3 to $5 \mathrm{~mm}$ larger than the diameter of the 'landing zone'. The ACP device is not designed to fill the LAA but to seal its ostium by means of the larger disk. As such, the ACP device could be a better choice when challenged with a more complex anatomy of the distal LAA or a proximal LAA lobe. The ACP device received a CE mark in 2008 and is currently used in clinical practice. (C-D) show the implantation of an ACP device in the regular way (C), or using the 'sandwich technique' when confronted with a chicken wing LAA with a short neck (D). (E) a cine image of a LA angiogram performed through a transseptal catheter following deployment of an ACP device (white arrow) inside the LAA - when properly positioned, the lobe has a typical 'tire' morphology with slight compression on the sides. (F) a TEE image of a properly deployed ACP device, showing absence of peri-device leaks, good alignment of the disk with the LA cavity, and absence of compression on the left upper pulmonary vein. Some images were reproduced with permission from Aryana et al. (2012). ${ }^{42}$ 

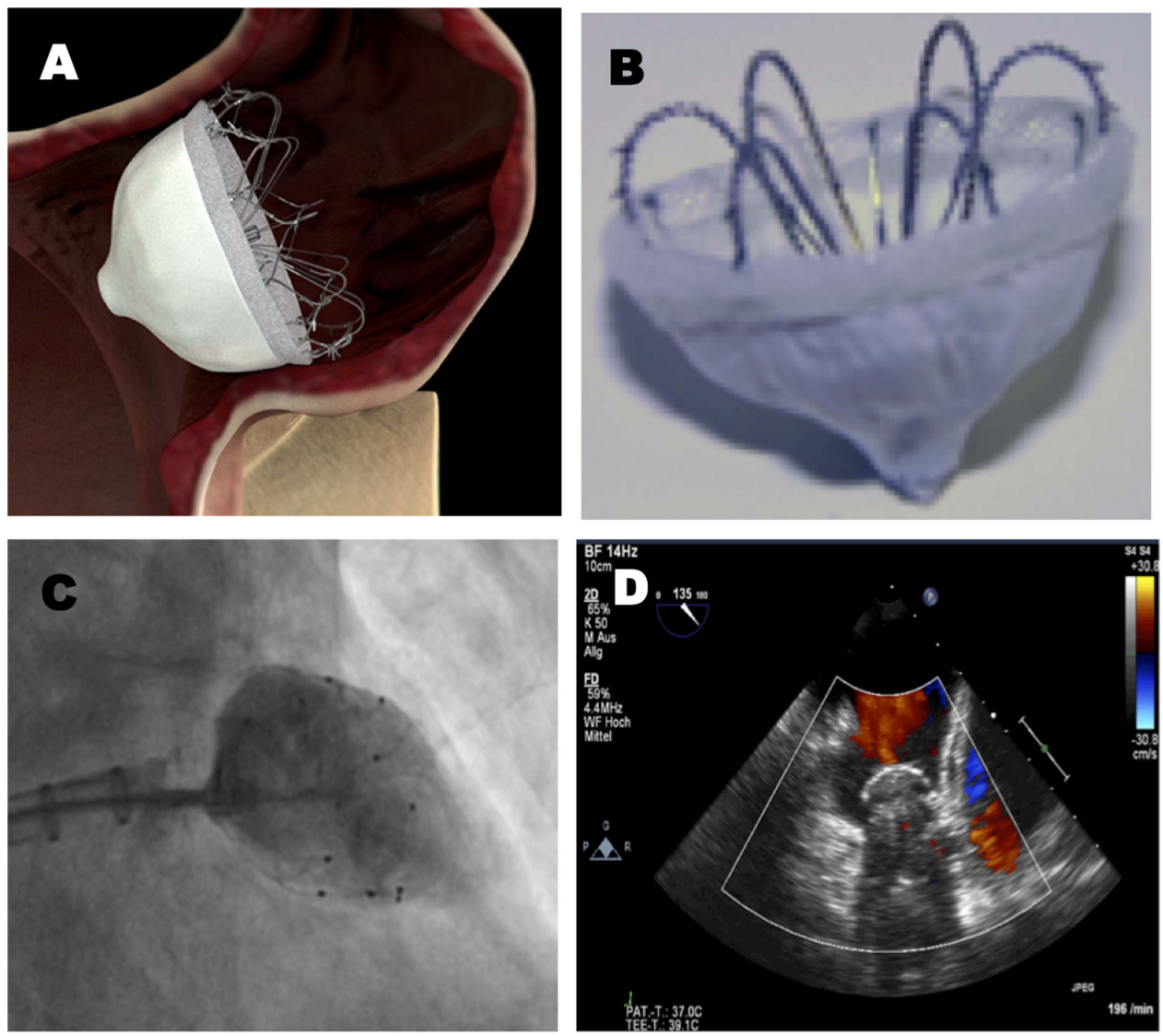

Figure 7 (A-B) the Coherex WaveCrest LAA occlusion system is the latest development in LAA occlusion devices. It consists of a nitinol frame with retractable coils and anchors to enable optimal device positioning. The device consists of a multi-composite membrane including a PTFE membrane on the LA side of the device, and a foam substrate on the LA-opposing surface to minimize residual leaks. Very recently, the WAVECREST I clinical trial was completed - CE Mark approval was obtained in September 2013. (C) a cine image showing contrast injection distally of the device (into the LAA) in order to assess complete LAA closure. (D) a TTE image confirming the device is well-seated and without leaks. Some images were presented by Franzen O. on EuroPCR $2013 .{ }^{43}$

Table 2 Possible complications of percutaneous LAA closure

\begin{tabular}{|c|c|c|}
\hline & $\begin{array}{l}\text { Short } \\
\text { term }\end{array}$ & $\begin{array}{l}\text { Long } \\
\text { term }\end{array}$ \\
\hline Cardiac perforation* & + & $(+)$ \\
\hline Pericardial effusion with tamponade $†$ & + & $(+)$ \\
\hline Device embolisation & + & + \\
\hline Device thrombosis & + & + \\
\hline $\begin{array}{l}\text { Stroke/TIA-thromboembolism, air } \\
\text { embolism }\end{array}$ & + & + \\
\hline $\begin{array}{l}\text { Vascular complications- } \\
\text { haematoma, bleeding, AV fistula } \\
\text { formation }\end{array}$ & + & $(+)$ \\
\hline \multicolumn{3}{|c|}{$\begin{array}{l}{ }^{*} \text { Cardiac perforation: pericardial effusion resulting in surgical } \\
\text { intervention/repair-due to transseptal puncture, or LAA closure } \\
\text { device which can perforate the LAA } \pm \text { pulmonary artery (acute or } \\
\text { after }>7 \text { days). }{ }^{73} 74 \\
\text { †Pericardial effusion with tamponade: pericardial effusion resulting } \\
\text { in percutaneous treatment/drainage or pericardial window. } \\
\text { LAA, left atrial appendage; TIA, transient ischemic attack; } \\
\text { AV, arteriovenous. }\end{array}$} \\
\hline
\end{tabular}

during the procedure after establishing an LA pressure of more than $10 \mathrm{~mm} \mathrm{Hg}$ by saline infusion.

\section{Device implantation}

Percutaneous LAA occlusion is usually performed under general anaesthesia and with TEE and fluoroscopic guidance. Antibiotic prophylaxis is administered prior to the procedure. Vascular access through a femoral vein is obtained and the delivery system is introduced by transseptal puncture using a standard transseptal needle and sheath. In order to have good alignment with the axis of the LAA, the puncture site is preferably inferior and posterior in the fossa. Additionally, different curves of sheaths are available to access the LAA. After the puncture, a bolus of unfractionated heparin should be given to achieve an activated clotting time (ACT) $>250 \mathrm{~s}$. TEE (or intracardiac echocardiography (ICE)) and contrast angiography of the LAA (right anterior oblique $30^{\circ}$ / cranial $30^{\circ}$ ) are used to measure the LAA dimensions (ostium, neck width, depth)—based on these 
measurements, the size of the device is chosen. The optimal C-arm angulation for implantation can vary widely from patient to patient. The positioning of the device in the LAA cavity is ensured by TEE/ICE and fluoroscopy (figure 3). The device is deployed by withdrawing the sheath over the device (to reduce the risk of perforation). Once in position, the device stability is confirmed by a 'tug test', and complete sealing is verified by colour Doppler imaging. Finally, the device is released from the delivery cable and possible complications such as pericardial effusion are ruled out. The individual steps may vary with the different devices. ${ }^{13}{ }^{44-46}$

\section{Available devices}

The percutaneous LAA transcatheter occlusion (PLAATO) device was the first to be successfully implanted in humans; however, this device is no longer available after withdrawal from the market in 2006. Until now, the WATCHMAN and ACP device have been most widely used in clinical practice. Very recently, the Coherex WaveCrest device also obtained CE Mark approval for percutaneous LAA occlusion. ${ }^{47} 48$

A detailed description of these different LAA occluders can be found in figures 4-7. References to step-by-step descriptions of a percutaneous LAA closure procedure with a WATCHMAN and ACP device can be found in online supplementary file $1 .^{49-51}$ Surgical/thoracoscopic LA appendectomy and the epicardial LARIAT suture delivery device are described elsewhere. ${ }^{52-54}$

\section{Postprocedural considerations}

Many centres perform a chest X-ray and TTE before discharge in order to rule out device embolisation and pericardial effusion. After 45 days, a control TEE is suggested to verify complete sealing of the LAA and the absence of a thrombus.

Various antithrombotic regimens have been used after LAA closure. In the PROTECT AF trial, OAC was given for 45 days and patients discontinued OAC if the 45-day TEE control showed either complete closure of the LAA or if the jet width of the residual peridevice flow was $<5 \mathrm{~mm}$. After stopping OAC therapy, patients were given dual antiplatelet therapy (DAPT) with acetylsalicylic acid (ASA) and clopidogrel until completion of the 6-month TEE control, after which ASA monotherapy was continued indefinitely. In $14 \%$ of patients, OAC was continued beyond 45 days, and in $8 \%$ of patients, OAC was continued beyond 6 months because of incomplete LAA closure or device thrombosis. ${ }^{55}$

A more recent study-the ASAP registry-of 150 patients receiving the WATCHMAN occluder reports that WATCHMAN implantation can be safely performed without OAC transition and that DAPT prescribed for 6 months followed by ASA alone may be an adequate antithrombotic regimen. ${ }^{56}$ With the use of the ACP device, OAC has been avoided and DAPT has been prescribed for variable durations, from 1 to 6 months after implantation, followed by ASA alone.
A literature search, however, shows that the incidence of device thrombosis is not insignificant, with rates ranging from $4 \%$ to $17 \% .^{56-58}$ The incidence of thrombus formation is more frequent in the first few weeks/ months after implantation and significantly declines with complete endothelisation of the occluder surface. In cases of device thrombosis, subcutaneous heparin is typically given for 2 weeks followed by TEE, and DAPT therapy is extended for a longer period.

Interestingly, a recent study involving 34 ACP device implantations reported that the risk for thrombus formation on the device was increased in patients with a high platelet count, high stroke risk score and low LV ejection fraction. ${ }^{57}$ These findings underline the importance of close follow-up of such patients and the need for a large prospective trial to address the optimal antithrombotic regime and duration of therapy in these high-risk patients.

In clinical practice today, DAPT is prescribed for the first 45 days after LAA closure and clopidogrel can be stopped if major peridevice leaks and device thrombosis are ruled out at the 45-day TEE control. After 6 months, ASA treatment may or may not be stopped completely if no other indication for antiplatelet therapy exists. In patients with a very high bleeding risk, it may be considered to give only one antiplatelet drug from right after the procedure. Only in very exceptional cases, an LAA closure device may be implanted in patients who cannot take any antithrombotic or anticoagulant therapy. In patients with a stroke under anticoagulant therapy, we believe it should be considered to continue low-dose NOAC therapy after LAA closure. Clearly, more studies are needed to determine the optimal postprocedural antithrombotic strategy.

It is noteworthy that it was recently reported that also after percutaneous LAA exclusion with the Lariat snare device-in which no intracavitary device is left behindthrombus formation at the LAA ostium can occur. ${ }^{59}$ Therefore, postprocedural antiplatelet therapy is also indicated for this device.

\section{Procedural safety and short-term outcome}

Percutaneous LAA occlusion is a procedure for stroke 'prevention' in patients with AF, and therefore procedural safety is paramount.

In the PROTECT AF trial (2009)-comparing the WATCHMAN device $(n=463)$ to warfarin $(n=244)$ in patients with $\mathrm{AF}$ with increased stroke risk-the primary safety endpoint (composite of pericardial effusion, device embolisation, major bleeding and procedure-related stroke) was increased in the WATCHMAN group (7.4 events/100 patient-years) when compared with the control OAC group (4.4 events/100 patient-years). Most of the events occurred within the first 7 days after device implantation-about $50 \%$ were pericardial effusions requiring drainage..$^{55}$

More recent data, however, from the CAP registry $(\mathrm{n}=566$, WATCHMAN $),{ }^{60}$ the PREVAIL study $(\mathrm{n}=269$, 
Table 3 Procedural safety and short-term outcome of percutaneous LAA occlusion

\begin{tabular}{|c|c|c|c|c|c|c|c|c|}
\hline Reference & $\begin{array}{l}\text { Patients } \\
\text { (n) }\end{array}$ & $\begin{array}{l}\text { Successful } \\
\text { implantation } \\
(\%)\end{array}$ & $\begin{array}{l}\text { Pericardial } \\
\text { effusion } \\
(\%)\end{array}$ & $\begin{array}{l}\text { Device } \\
\text { embolisation } \\
(\%)\end{array}$ & $\begin{array}{l}\text { Bail-out } \\
\text { surgery } \\
(\%)\end{array}$ & $\begin{array}{l}\text { Stroke/ } \\
\text { embolism } \\
(\%)\end{array}$ & $\begin{array}{l}\text { Major } \\
\text { bleeding } \\
(\%)\end{array}$ & Death \\
\hline \multicolumn{9}{|l|}{ PLAATO } \\
\hline Sievert et $a l^{75}$ & 15 & 100 & 6.7 & 0 & 0 & 0 & 0 & 0 \\
\hline Hanna et $a l^{76}$ & 11 & 100 & 0 & 0 & 0 & 0 & 0 & 0 \\
\hline Ostermayer et $a l^{p 7}$ & 111 & 97 & 4.6 & 0 & 0.9 & 0 & - & 0.9 \\
\hline El-Chami et $a l^{78}$ & 11 & 100 & 0 & 0 & 0 & 0 & - & 0 \\
\hline De Meester $(2008)^{79}$ & 10 & 90 & 0 & 11.1 & 0 & 0 & - & 0 \\
\hline Ussia et $a^{\beta 0}$ & 20 & 90 & 5.6 & 0 & 0 & 0 & 0 & 0 \\
\hline Park et $a^{\beta 1}$ & 73 & 100 & 1.4 & 1.4 & 1.4 & 1.4 & - & 1.4 \\
\hline Block et a ${ }^{\beta 2}$ & 64 & 98 & 1.6 & - & 1.6 & - & - & 1.6 \\
\hline Bayard et $a p^{\beta 3}$ & 180 & 90 & 3.3 & 0.6 & 1.1 & - & - & 1.1 \\
\hline Viles-Gonzalez et a/64 & 22 & 100 & 4.5 & 0 & 0 & 0 & - & 0 \\
\hline \multicolumn{9}{|l|}{ Watchman } \\
\hline Sick et $a^{\beta 4}$ & 66 & 88 & 3.0 & 3 & 1.5 & 0 & 1.5 & 0 \\
\hline Holmes et $\left.a\right|^{55}$ & 463 (PAF) & 88 & 4.8 & 0.6 & 1.9 & 0.2 & - & 0 \\
\hline Reddy et $a^{60}$ & 460 (CAP) & 95 & 2.2 & 0 & 0.2 & 0 & 0.7 & 0 \\
\hline Kim et $a \beta^{35}$ & 5 & 100 & 0 & 0 & 0 & 0 & 0 & 0 \\
\hline Swaans et $a{ }^{\beta 6}$ & 10 & 100 & 0 & 10.0 & 0 & 0 & 10.0 & 0 \\
\hline Bai et $a l^{\beta 7}$ & 58 & 100 & 1.7 & 0 & 0 & 0 & 0 & 0 \\
\hline Swaans et $a^{\beta 8}$ & 30 & 100 & 0 & 3.3 & 0 & 0 & 0 & 0 \\
\hline Reddy et $a^{{ }^{6}}$ & 150 & 95 & 1.3 & 1.3 & - & 0 & - & 0 \\
\hline \multicolumn{9}{|l|}{$\mathrm{ACP}$} \\
\hline Park et $a{ }^{89}$ & 137 & 96 & 3.6 & 1.5 & - & 2.2 & 0 & 0 \\
\hline Lam et $a \rho^{\beta 0}$ & 20 & 95 & 0 & 0 & 0 & - & 0 & 0 \\
\hline Montenegro et $a^{\rho^{1}}$ & 5 & 100 & 0 & 0 & 0 & 0 & 0 & 0 \\
\hline Danna et $a^{\rho^{2}}$ & 37 & 92 & 2.9 & 5.9 & 0 & 0 & - & 0 \\
\hline López-Mínguez et al ${ }^{72}$ & 35 & 97 & 0 & 0 & 0 & 0 & 0 & 0 \\
\hline Helsen et $a \rho^{\beta 3}$ & 15 & 100 & 0 & 0 & 0 & 6.7 & 0 & 0 \\
\hline Nietlispach et $a^{\rho 4 *}$ & 152 & 96 & 2.6 & 4.6 & 3.3 & 2.0 & - & 0 \\
\hline Freixa et $\left.a\right|^{\beta 3}$ & 42 & 100 & 0 & 0 & 0 & 0 & 0 & 0 \\
\hline Urena et a ${ }^{{ }^{5}}$ & 52 & 98 & 1.9 & 1.9 & 0 & 0 & 3.8 & 0 \\
\hline Streb et $a^{\rho^{6}}$ & 21 & 95 & 4.8 & 0 & 0 & 0 & 0 & 0 \\
\hline Meerkin et $a \rho^{77}$ & 100 & 100 & 1.0 & 0 & 0 & 0 & 0 & 0 \\
\hline Faustino et $a^{\rho 8}$ & 21 & 96 & 0 & 0 & 0 & 0 & 0 & 0 \\
\hline Plicht et $a{ }^{57}$ & 34 & 100 & 2.9 & 0 & 0 & 0 & 5.9 & 0 \\
\hline Apostolos et a/62 & 969 & 97 & 1.2 & 0.2 & - & 0.7 & 1.2 & 0.6 \\
\hline
\end{tabular}

${ }^{*}$ Nietlispach et $a^{\rho^{4}}$ : non-dedicated LAA occlusion devices were used in 32 patients, dedicated (ACP) in 120 patients.

ACP, Amplatzer cardiac plugs; LAA, left atrial appendage.

WATCHMAN $)^{61}$ and a large multicentre study involving the ACP device $(\mathrm{n}=969)^{62}$ show improved procedural safety-complication rates within 7 days were $4.1 \%, 4.4 \%$ and $4.1 \%$, respectively, as compared with $>7 \%$ in the initial PROTECT AF trial (2009). These lower rates of periprocedural major adverse events can be ascribed to a better understanding of the procedure and an operator learning curve effect.

A list of possible complications can be found in table 2. A detailed overview of procedural safety and short-term outcome data from the different LAA closure devices is given in table 3 .

\section{Intermediate/long-term clinical outcome}

Most of the studies published until now are nonrandomised cohort studies or prospectively collected, retrospectively analysed multicentre registries, which demonstrate that annualised stroke rates after percutaneous LAA closure are favourable when compared with expected stroke rates as predicted by a $\mathrm{CHADS}_{2}$ score (table 4).

The only prospective, randomised trial so far published is the PROTECT AF trial in which 707 patients with NVAF were randomly assigned in a 2:1 ratio to either percutaneous LAA occlusion with the WATCHMAN device or to warfarin therapy. The study was designed to assess the non-inferiority of the device against chronic OAC therapy. Patients with paroxysmal, persistent or permanent NVAF were eligible for enrolment if they had a $\mathrm{CHADS}_{2}$ risk score $\geq 1$. The trial confirmed the non-inferiority of WATCHMAN LAA occlusion compared with OAC therapy regarding the primary efficacy endpoint-a composite of stroke, systemic embolism and cardiovascular death $(\mathrm{RR}=0.62$, $95 \%$ CI 0.35 to 1.25$)$. The probability of non-inferiority of the intervention was $>99.9 \% .^{55}$ 
Table 4 Intermediate/long-term outcome data following percutaneous LAA occlusion

\begin{tabular}{|c|c|c|c|c|c|c|c|c|}
\hline \multirow[b]{2}{*}{ Reference } & \multirow[b]{2}{*}{ Patients (n) } & \multirow{2}{*}{$\begin{array}{l}\text { CHADS }_{2} \\
\text { (mean) }\end{array}$} & \multirow{2}{*}{$\begin{array}{l}\text { Follow-up } \\
\text { (m, mean) }\end{array}$} & \multirow{2}{*}{ Stroke } & \multirow{2}{*}{$\begin{array}{l}\text { Observed } \\
\text { annual } \\
\text { stroke rate (\%) }\end{array}$} & \multicolumn{3}{|c|}{$\begin{array}{l}\text { Expected annual stroke rate } \\
\left(\sim \mathrm{CHADS}_{2}\right)^{\star}\end{array}$} \\
\hline & & & & & & Ref (\%) & Gage (\%) & w/OAC (\%) \\
\hline Sievert et $a l^{75}$ & 15 & - & 1 & - & - & - & - & - \\
\hline Hanna et $a l^{76}$ & 11 & 2.4 & 6 & - & - & - & 4.8 & 1.9 \\
\hline Ostermayer et $a^{p 7}$ & 111 & 2.5 & 10 & $2 / 108$ & 2.2 & 6.3 & 5.0 & 2.0 \\
\hline Ussia et $\left.a\right|^{\beta 0}$ & 20 & 3.0 & 40 & 0 & 0 & 6.4 & 5.9 & 2.4 \\
\hline Park et $a^{\beta 1}$ & 73 & 2.5 & 24 & 0 & 0 & 3.5 & 5.0 & 2.0 \\
\hline Block et $a \beta^{\beta 2}$ & 64 & 2.6 & 45 & $9 / 64$ & 3.8 & 6.6 & 5.1 & 2.1 \\
\hline Bayard et $a^{\beta 3}$ & 180 & 3.1 & 10 & $3 / 180$ & 2.3 & 6.6 & 6.2 & 2.5 \\
\hline Viles-Gonzalez et a ${ }^{64}$ & 22 & 3.6 & 58 & $4 / 22$ & 3.6 & 6.8 & 7.5 & 3.0 \\
\hline Kim et $a^{\beta 5}$ & 5 & 3.2 & 2 & - & - & - & 6.4 & 2.6 \\
\hline Swaans et $a l^{\beta 6}$ & 10 & 2.8 & 1.5 & - & - & - & 5.5 & 2.2 \\
\hline Bai et $a^{\beta 7}$ & 58 & 2.2 & 26 & $1 / 58$ & 0.7 & - & 4.4 & 1.8 \\
\hline Swaans et $\left.a\right|^{\beta 8}$ & 30 & 2.6 & 12 & 0 & 0 & - & 5.0 & 2.0 \\
\hline Reddy et $a^{56}$ & 150 & 2.8 & 14 & $4 / 150$ & 2.3 & 7.3 & 5.5 & 2.2 \\
\hline \multicolumn{9}{|l|}{$\mathrm{ACP}$} \\
\hline Park et $a{ }^{\beta 9}$ & 137 & - & - & - & - & - & - & - \\
\hline Lam et a ${ }^{\rho 0}$ & 20 & 2.3 & 12 & 0 & 0 & 5.3 & 4.6 & 1.8 \\
\hline Montenegro et $a^{\rho^{1}}$ & 5 & 4.0 & 14 & 0 & 0 & 5.5 & 8.5 & 3.4 \\
\hline Danna et $a^{\rho^{2}}$ & 37 & 3.1 & 12 & $1 / 34$ & 2.9 & 5.9 & 6.2 & 2.5 \\
\hline López-Mínguez et al ${ }^{72}$ & 35 & 2.4 & 21 & $1 / 35$ & 2.9 & - & 4.8 & 1.9 \\
\hline Apostolos et a/2 & 969 & 2.7 & 15 & $25 / 969$ & 2.1 & 5.6 & 5.3 & 2.1 \\
\hline
\end{tabular}

At the Heart Rhythm Society's 34th Annual Scientific Sessions (2013), 4-year follow-up results from the PROTECT AF trial were presented. The primary efficacy endpoint occurred in $2.3 \%$ of the device group vs $3.8 \%$ of the warfarin group $(\mathrm{RR}=0.60,95 \%$ CI 0.41 to 1.05$)$, demonstrating a $40 \%$ relative risk reduction in primary efficacy in the WATCHMAN group. Cardiovascular death occurred in $1.0 \%$ of the device group vs $2.4 \%$ of the warfarin group $(\mathrm{RR}=0.40,95 \% \mathrm{CI} 0.21$ to $0.72, \mathrm{p}<0.05)$. The rate of haemorrhagic stroke was $0.2 \%$ in the device group vs $1 \%$ in the warfarin group $(\mathrm{RR}=0.18,95 \% \mathrm{CI}$ 0.04 to $0.60, \mathrm{p}<0.05)$. In conclusion, these long-term follow-up data seem to provide additional support for LAA closure as a potential alternative to OAC therapy in patients with NVAF. $^{63}$
Finally, we also looked at the prevalence and impact of residual peridevice leaks after LAA closure. Peridevice leaks are typically evaluated by colour Doppler (TEE) and classified as: (1) severe-multiple jets or free flow; (2) major-jet width $>3 \mathrm{~mm}$; (3) moderate-jet width of $1-3 \mathrm{~mm}$ and (4) minor-jet width $<1 \mathrm{~mm}$. Major residual leaks have been reported in as many as $62 \%$, $32 \%$ and $10 \%$ of the patients after PLAATO, WATCHMAN and ACP device implantation, respectively. The lower rate of residual leak observed after ACP implantation may be related to the double-disk structure of the ACP, which may contribute to a better sealing of the LAA orifice. Most importantly, however, the presence of residual peridevice leaks has never been associated with cardioembolic events in any of these studies. ${ }^{64-66}$ 
Typically, when detecting major residual peridevice leaks, OAC therapy is continued or restarted for several weeks/months until the next control TEE in the hope of a complete closure or jet width $<3 \mathrm{~mm}$. Still, more research about this issue is clearly warranted.

\section{DISCUSSION}

Since the first percutaneous LAA closure in 2002, a rapidly growing number of studies have shown that this strategy can be a safe and efficacious therapy in the management of patients with NVAF for whom OAC is indicated but who are at a high risk of bleeding. As a result, the WATCHMAN device received substantial endorsement from a Food and Drug Administration (FDA) advisory panel in December 2013-a definitive FDA approval is expected later this year.

Although the only RCTs available until now (PROTECT AF, PREVAIL) included only patients who were eligible for OAC therapy, ${ }^{55} 61$ we believe that the current data only justify the use of this therapeutic option in patients with contraindications to OAC therapy. Patients with NVAF who have no contraindication(s) for OAC should have LAA occlusion only in exceptional cases. Accordingly, the updated ESC guidelines recommend LAA occlusion in patients with $\mathrm{AF}$ who are at a high risk of stroke and who have contraindications to long-term OAC therapy. ${ }^{10}$

In future studies, it will be important to identify patients who may benefit the most from percutaneous LAA closure as a valid strategy for stroke prevention. It has been reported that LAA closure has a larger 'net clinical benefit' when compared with OAC therapy in patients with a high stroke risk-the higher the stroke risk, the larger the 'net clinical benefit' of LAA occlusion. ${ }^{26}$ On the other hand, patients at a high risk for thromboembolism-high platelet count, high $\mathrm{CHADS}_{2}$ score, LV dysfunction or prior strokehave also been shown to be at a higher risk for LA cavity thrombus ${ }^{27}$ and device thrombosis. ${ }^{57}$ Clearly, more studies are warranted to investigate whether some subgroups are more suitable for LAA closure than others.

When starting up an LAA closure programme, it is important to understand that safety is the most 'vulnerable' aspect of the procedure-a low complication rate is a 'must' in order to establish a successful programme. Moreover, one should realise that imaging is an integral part of planning, performing and follow-up of LAA closure procedures. In addition, the LAA has a highly variable anatomical structure and may offer various procedural challenges.

Finally, we believe that future studies should attempt to (1) further refine the selection of patients most suitable for LAA closure, (2) explore the usefulness of a more tailored postprocedural antithrombotic therapyadapted to the individual thrombotic and bleeding risk profile, (3) investigate the prevalence and impact of peridevice leaks and device thrombosis in larger cohorts and (4) contribute to further design improvement(s) of LAA closure devices.

\section{CONCLUSION}

Percutaneous LAA occlusion has been shown to be a safe, efficacious and cost-effective strategy ${ }^{67}$ for stroke prevention in patients with NVAF with increased stroke and bleeding risk. However, since these high-risk patients were typically excluded or under-represented in the available RCTs, additional comparative studies of percutaneous LAA closure versus OAC therapy are needed before this procedure can be recommended for clinical routine.

Contributors ODB collected and analysed all data and wrote the first draft of the manuscript. OWF contributed essentially to the content of the article. SA, $\mathrm{NI}, \mathrm{NV}, \mathrm{EJ}, \mathrm{SP}, \mathrm{TDWK}, \mathrm{PM}$ and LS revised the manuscript critically and approved the final version for publication. OWF is the guarantor.

Funding Grant funding (St Jude Medical) for research.

Competing interests None.

Provenance and peer review Not commissioned; externally peer reviewed.

Data sharing statement No additional data are available.

Open Access This is an Open Access article distributed in accordance with the Creative Commons Attribution Non Commercial (CC BY-NC 3.0) license, which permits others to distribute, remix, adapt, build upon this work noncommercially, and license their derivative works on different terms, provided the original work is properly cited and the use is non-commercial. See: http:// creativecommons.org/licenses/by-nc/3.0/

\section{REFERENCES}

1. Wolf PA, Abbott RD, Kannel WB. Atrial fibrillation as an independent risk factor for stroke: the Framingham Study. Stroke 1991;22:983-8.

2. Furberg CD, Psaty BM, Manolio TA, et al. Prevalence of atrial fibrillation in elderly subjects-the Cardiovascular Health Study. Am J Cardiol 1994;74:236-41.

3. Go AS, Hylek EM, Philips KA, et al. Prevalence of diagnosed atrial fibrillation in adults: national implications for rhythm management and stroke prevention: the AnTicoagulation and Risk Factors in Atrial Fibrillation (ATRIA) Study. JAMA 2001;285:2370-5.

4. Feinberg WM, Blackshear JL, Laupacis, et al. Prevalence, age distribution, and gender of patients with atrial fibrillation. Analysis and implications. Arch Intern Med 1995;155:469-73.

5. (No Author used). Risk factors for stroke and efficacy of antithrombotic therapy in atrial fibrillation. Analysis of pooled data from five randomized controlled trials. Arch Intern Med 1994;154:1449-57.

6. Benjamin EJ, Wolf PA, D'Agostino RB, et al. Impact of atrial fibrillation on the risk of death: the Framingham Heart Study. Circulation 1998;98:946-52.

7. Sandercock P, Bamford J, Dennis M, et al. Atrial fibrillation and stroke: prevalence in different types of stroke and influence on early and long term prognosis. BMJ 1992;305:1460-5.

8. Wolf PA, Benjamin EJ, Belanger AJ, et al. Secular trends in the prevalence of atrial fibrillation: the Framingham Study. Am Heart $J$ 1996;131:790-5.

9. Kannel WB, Wolf PA, Benjamin EJ, et al. Prevalence, incidence, prognosis, and predisposing conditions for atrial fibrillation: population-based estimates. Am J Cardiol 1998;82(8A):2N-9N.

10. Camm AJ, Lip GY, De Caterina R, et al. 2012 focused update of the ESC Guidelines for the management of atrial fibrillation: an update of the 2010 ESC Guidelines for the management of atrial fibrillation-developed with the special contribution of the European Heart Rhythm Association. Europace 2012;14:1385-413.

11. Glader EL, Sjolander M, Eriksson M, et al. Persistent use of secondary prevention drugs declines rapidly during the first 2 years after stroke. Stroke 2010;41:397-401. 
12. Landmesser U, Holmes DR Jr. Left atrial appendage closure: a percutaneous transcatheter approach for stroke prevention in atrial fibrillation. Eur Heart J 2012;33:698-704.

13. Lewalter T, Ibrahim R, Albers B, et al. An update and current expert opinions on percutaneous left atrial appendage occlusion for stroke prevention in atrial fibrillation. Europace 2013;15:652-6.

14. Connolly SJ, Ezekowitz MD, Yusuf S, et al. Dabigatran versus warfarin in patients with atrial fibrillation. $N$ Engl $J$ Med 2009;361:1139-51.

15. Patel MR, Mahaffey KW, Garg J, et al. Rivaroxaban versus warfarin in nonvalvular atrial fibrillation. N Engl J Med 2011;365:883-91.

16. Granger $\mathrm{CB}$, Alexander JH, McMurray JJ, et al. Apixaban versus warfarin in patients with atrial fibrillation. $N$ Engl $J$ Med 2011;365:981-92.

17. Bunch TJ, May HT, Bair TL, et al. Atrial fibrillation ablation patients have long-term stroke rates similar to patients without atrial fibrillation regardless of CHADS2 score. Heart Rhythm 2013;10:1272-7

18. Calkins H, Kuck KH, Cappato R, et al. HRS/EHRA/ECAS expert consensus statement on catheter and surgical ablation of atrial fibrillation: recommendations for patient selection, procedural techniques, patient management and follow-up, definitions, endpoints, and research trial design. Europace 2012;14:528-606.

19. Blackshear JL, Odell JA. Appendage obliteration to reduce stroke in cardiac surgical patients with atrial fibrillation. Ann Thorac Surg 1996;61:755-9.

20. Onalan O, Crystal E. Left atrial appendage exclusion for stroke prevention in patients with nonrheumatic atrial fibrillation. Stroke 2007;38(2 Suppl):624-30

21. Klein AL, Grimm RA, Murray RD, et al. Use of transesophageal echocardiography to guide cardioversion in patients with atrial fibrillation. N Engl J Med 2001;344:1411-20.

22. Whitlock RP, Healey JS, Connolly SJ. Left atrial appendage occlusion does not eliminate the need for warfarin. Circulation 2009;120:1927-32.

23. Meier P, Franzen O, Lansky AJ. Almanac 2013: novel non-coronary cardiac interventions. Heart 2013;99:1309-16.

24. Lip GY, Dagres N, Proclemer A, et al. Left atrial appendage occlusion for stroke prevention in atrial fibrillation in Europe: results of the European Heart Rhythm Association survey. Europace 2013;15:141-3.

25. Munkholm-Larsen S, Cao C, Yan TD, et al. Percutaneous atria appendage occlusion for stroke prevention in patients with atrial fibrillation: a systematic review. Heart 2012;98:900-7.

26. Gangireddy SR, Halperin JL, Fuster V, et al. Percutaneous left atrial appendage closure for stroke prevention in patients with atrial fibrillation: an assessment of net clinical benefit. Eur Heart $J$ 2012;33:2700-8.

27. Mahajan R, Brooks AG, Sullivan T, et al. Importance of the underlying substrate in determining thrombus location in atrial fibrillation: implications for left atrial appendage closure. Hear 2012;98:1120-6.

28. Alli O, Holmes DR Jr. Left atrial appendage occlusion for stroke prevention. Curr Probl Cardiol 2012;37:405-41.

29. Yu CM, Khattab AA, Bertog SC, et al. Mechanical antithrombotic intervention by LAA occlusion in atrial fibrillation. Nat Rev Cardio 2013;10:707-22.

30. Wang Y, Di Biase L, Horton RP, et al. Left atrial appendage studied by computed tomography to help planning for appendage closure device placement. J Cardiovasc Electrophysiol 2010;21:973-82.

31. Üçerler H, İkiz ZA, Özgür T. Human left atrial appendage anatomy and overview of its clinical significance. Anadolu Kardiyol Derg 2013:13:566-72.

32. Di Biase L, Santangeli $P$, Anselmino M, et al. Does the left atrial appendage morphology correlate with the risk of stroke in patients with atrial fibrillation? Results from a multicenter study. J Am Coll Cardiol 2012;60:531-8.

33. Freixa X, Tzikas A, Basmadjian A, et al. The chicken-wing morphology: an anatomical challenge for left atrial appendage occlusion. J Interv Cardiol 2013;26:509-14.

34. Landmesser U. Catheter-based LAA occlusion: promising experiences. Cardiology updates; Davos, 2013, assets.escardio.org.

35. Kimura T, Takatsuki S, Inagawa K, et al. Anatomical characteristics of the left atrial appendage in cardiogenic stroke with low $\mathrm{CHADS}_{2}$ scores. Heart Rhythm 2013;10:921-5.

36. Khurram IM, Dewire J, Mager M, et al. Relationship between left atrial appendage morphology and stroke in patients with atrial fibrillation. Heart Rhythm 2013;10:1843-9.

37. Beinart R, Heist EK, Newell JB, et al. Left atrial appendage dimensions predict the risk of stroke/TIA in patients with atrial fibrillation. J Cardiovasc Electrophysiol 2011;22:10-15.
38. Chue CD, de Giovanni J, Steeds RP. The role of echocardiography in percutaneous left atrial appendage occlusion. Eur $J$ Echocardiogr 2011;12:i3-10.

39. Lockwood SM, Alison JF, Obeyesekere MN, et al. Imaging the left atrial appendage prior to, during, and after occlusion. JACC Cardiovasc Imaging 2011;4:303-6.

40. Nucifora G, Faletra FF, Regoli F, et al. Evaluation of the left atrial appendage with real-time 3-dimensional transesophageal echocardiography. Implications for catheter-based left atrial appendage closure. Circ Cardiovasc Imaging 2011;4:514-23.

41. Budge LP, Shaffer KM, Moorman JR, et al. Analysis of in vivo left atrial appendage morphology in patients with atrial fibrillation: a direct comparison of transesophageal echocardiography, planar cardiac CT, and segmented three-dimensional cardiac CT. J Interv Card Electrophysiol 2008;23:87-93.

42. Krishnaswamy A, Patel NS, Ozkan A, et al. Planning left atrial appendage occlusion using cardiac multidetector computed tomography. Int J Cardiol 2012;158:313-17.

43. Heist EK, Refaat M, Danik SB, et al. Analysis of the left atrial appendage by magnetic resonance angiography in patients with atrial fibrillation. Heart Rhythm 2006;3:1313-18.

44. Ho IC, Neuzil P, Mraz T, et al. Use of intracardiac echocardiography to guide implantation of a left atrial appendage occlusion device (PLAATO). Heart Rhythm 2007;4:567-71

45. Blendea D, Heist EK, Danik SB, et al. Analysis of the left atria appendage morphology by intracardiac echocardiography in patients with atrial fibrillation. J Interv Card Electrophysiol 2011;31:191-6.

46. MacDonald ST, Newton JD, Ormerod OJ. Intracardiac echocardiography off piste? Closure of the left atrial appendage using ICE and local anesthesia. Catheter Cardiovasc Interv 2011;77:124-7.

47. Aryana A, Saad EB, d'Avila A. Left atrial appendage occlusion and ligation devices: what is available, how to implement them, and how to manage and avoid complications. Curr Treat Options Cardiovasc Med 2012;14:503-19.

48. Franzen $\mathrm{O}$, Reddy V, Worthley $\mathrm{S}$, et al. Clinical experience with the Coherex WaveCrest ${ }^{\mathrm{rM}}$ LAA occlusion system. Acute results from the WaveCrest I trial. Paris: Scientific Session at EuroPCR, 2013.

49. Möbius-Winkler S, Sandri M, Mangner N, et al. The WATCHMAN left atrial appendage closure device for atrial fibrillation. $J$ Vis Exp 2012:3671.

50. Swaans MJ, Alipour A, Rensing BJ, et al. Catheter ablation in combination with left atrial appendage closure for atrial fibrillation. $J$ Vis Exp 2013:e3818.

51. Park JW. Implantation of the AMPLATZER ${ }^{\mathrm{TM}}$ Cardiac Plug: tips and tricks. Herzschrittmacherther Elektrophysiol 2013;24:33-8.

52. Ohtsuka T, Ninomiya M, Nonaka T, et al. Thoracoscopic stand-alone left atrial appendectomy for thromboembolism prevention in nonvalvular atrial fibrillation. J Am Coll Cardiol 2013;62:103-7.

53. Bartus K, Han FT, Bednarek J, et al. Percutaneous left atrial appendage suture ligation using the LARIAT device in patients with atrial fibrillation. Initial clinical experience. J Am Coll Cardiol 2013;62:108-18.

54. Stone D, Byrne T, Pershad A. Early results with the LARIAT device for left atrial appendage exclusion in patients with atrial fibrillation at high risk for stroke and anticoagulation. Catheter Cardiovasc Interv 2013. doi:10.1002/ccd.25065

55. Holmes DR, Reddy VY, Turi ZG, et al. Percutaneous closure of the left atrial appendage versus warfarin therapy for prevention of stroke in patients with atrial fibrillation: a randomised non-inferiority trial. Lancet 2009;374:534-42.

56. Reddy VY, Möbius-Winkler S, Miller MA, et al. Left atrial appendage closure with the Watchman device in patients with a contraindication for oral anticoagulation: the ASAP study (ASA Plavix Feasibility Study with Watchman Left Atrial Appendage Closure Technology). J Am Coll Cardiol 2013;61:2551-6.

57. Plicht B, Konorza TF, Kahlert $\mathrm{P}$, et al. Risk factors for thrombus formation on the Amplatzer Cardiac Plug after left atrial appendage occlusion. JACC Cardiovasc Interv 2013;6:606-13.

58. Krumsdorf $\mathrm{U}$, Ostermayer $\mathrm{S}$, Billinger $\mathrm{K}$, et al. Incidence and clinical course of thrombus formation on atrial septal defect and patent foramen ovale closure devices in 1,000 consecutive patients. J Am Coll Cardiol 2004;43:302-9.

59. Gafoor S. TEE follow-up: thrombus and residual leak. CSI-LAA focus congress, Frankfurt, 2013.

60. Reddy VY, Holmes D, Doshi SK, et al. Safety of percutaneous left atrial appendage closure: results from the Watchman Left Atrial Appendage System for Embolic Protection in Patients with AF (PROTECT AF) clinical trial and the Continued Access Registry. Circulation 2011;23:417-24 
61. Holmes D. Preliminary results of the randomized trial of $L A A$ closure vs warfarin for stroke/thromboembolic prevention in patients with non-valvular atrial fibrillation (PREVAIL) -late breaking clinical trial. American College of Cardiology (ACC) 2013 Scientific Sessions. San Francisco, 2013-based on press release by Boston Scientific, ultimately not presented.

62. Apostolos T. LAAO for stroke prevention in AF: multicenter experience with the Amplatzer Cardiac Plug (ACP). Transcatheter Cardiovascular Therapeutics (TCT) 2013 Scientific Sessions. San Francisco, 2013.

63. Reddy V. Long term results of PROTECT AF: the mortality effects of left atrial appendage closure versus warfarin for stroke prophylaxis in AF-late breaking clinical trial. Heart Rhythm Society (HRS) 2013 Scientific Sessions. Denver, 2013.

64. Viles-Gonzalez JF, Reddy VY, Petru J, et al. Incomplete occlusion of the left atrial appendage with the percutaneous left atrial appendage transcatheter occlusion device is not associated with increased risk of stroke. J Interv Card Electrophysiol 2012;33:69-75.

65. Viles-Gonzalez JF, Kar S, Douglas P, et al. The clinical impact of incomplete left atrial appendage closure with the Watchman Device in patients with atrial fibrillation: a PROTECT AF (Percutaneous Closure of the Left Atrial Appendage Versus Warfarin Therapy for Prevention of Stroke in Patients with Atrial Fibrillation) substudy. J Am Coll Cardiol 2012;59:923-9.

66. Freixa X, Tzikas A, Sobrino A, et al. Left atrial appendage closure with the Amplatzer ${ }^{\mathrm{TM}}$ Cardiac Plug: impact of shape and device sizing on follow-up leaks. Int J Cardiol 2013;168:1023-7.

67. Singh SM, Micieli A, Wijeysundera HC. Economic evaluation of percutaneous left atrial appendage occlusion, dabigatran, and warfarin for stroke prevention in patients with nonvalvular atrial fibrillation. Circulation 2013;127:2414-23.

68. Gage BF, Waterman AD, Shannon W, et al. Validation of clinical classification schemes for predicting stroke: results from the National Registry of Atrial Fibrillation. JAMA 2001; 285:2864-70.

69. Gage BF, van Walraven C, Pearce L, et al. Selecting patients with atrial fibrillation for anticoagulation: stroke risk stratification in patients taking aspirin. Circulation 2004;110:2287-92.

70. Olesen JB, Lip GY, Hansen ML, et al. Validation of risk stratification schemes for predicting stroke and thromboembolism in patients with atrial fibrillation: nationwide cohort study. BMJ 2011;342:d124.

71. Pisters R, Lane DA, Nieuwlaat R, et al. A novel user-friendly score (HAS-BLED) to assess 1-year risk of major bleeding in patients with atrial fibrillation: the Euro Heart Survey. Chest 2010;138:1093-100.

72. López-Mínguez JR, Eldoayen-Gragera J, González-Fernández R, et al. Immediate and one-year results in 35 consecutive patients after closure of left atrial appendage with the Amplatzer Cardiac Plug. Rev Esp Cardiol 2013;66:90-7.

73. Bianchi G, Solinas M, Gasbarri T, et al. Pulmonary artery perforation by plug anchoring system after percutaneous closure of left appendage. Ann Thorac Surg 2013;96:e3-5.

74. Sepahpour A, Ng MK, Storey P, et al. Death from pulmonary artery erosion complicating implantation of percutaneous left atrial appendage occlusion device. Heart Rhythm 2013;10:1810-1.

75. Sievert H, Lesh MD, Trepels T, et al. Percutaneous left atrial appendage transcatheter occlusion to prevent stroke in high-risk patients with atrial fibrillation: early clinical experience. Circulation 2002;105:1887-9.

76. Hanna IR, Kolm P, Martin R, et al. Left atrial structure and function after percutaneous left atrial appendage transcatheter occlusion (PLAATO): six-month echocardiographic follow-up. J Am Coll Cardiol 2004;43:1868-72.

77. Ostermayer SH, Reisman M, Kramer PH, et al. Percutaneous left atrial appendage transcatheter occlusion (PLAATO system) to prevent stroke in high-risk patients with non-rheumatic atrial fibrillation: results from the international multi-center feasibility trials. J Am Coll Cardiol 2005;46:9-14.

78. El-Chami MF, Grow P, Eilen D, et al. Clinical outcomes three years after PLAATO implantation. Catheter Cardiovasc Interv 2007:69:704-7.

79. De Meester P, Thijs V, Van Deyk K, et al. Prevention of stroke by percutaneous left atrial appendage closure: short term follow-up. Int J Cardiol 2010;142:195-6.

80. Ussia GP, Mulè M, Cammalleri V, et al. Percutaneous closure of left atrial appendage to prevent embolic events in high-risk patients with chronic atrial fibrillation. Catheter Cardiovasc Interv 2009;74:217-22.

81. Park JW, Leithäuser B, Gerk U, et al. Percutaneous left atrial appendage transcatheter occlusion (PLAATO) for stroke prevention in atrial fibrillation: 2-year outcomes. J Invasive Cardiol 2009:21:446-50.

82. Block PC, Burstein S, Casale PN, et al. Percutaneous left atrial appendage occlusion for patients in atrial fibrillation suboptimal for warfarin therapy: 5-year results of the PLAATO (Percutaneous Left Atrial Appendage Transcatheter Occlusion) Study. JACC Cardiovasc Interv 2009;2:594-600.

83. Bayard YL, Omran H, Neuzil P, et al. PLAATO (Percutaneous Left Atrial Appendage Transcatheter Occlusion) for prevention of cardioembolic stroke in non-anticoagulation eligible atrial fibrillation patients: results from the European PLAATO study. Eurolntervention 2010;6:220-6.

84. Sick PB, Schuler G, Hauptmann KE, et al. Initial worldwide experience with the WATCHMAN left atrial appendage system for stroke prevention in atrial fibrillation. J Am Coll Cardiol 2007;49:1490-5

85. Kim YL, Joung B, On YK, et al. Early experience using a left atrial appendage occlusion device in patients with atrial fibrillation. Yonsei Med J 2012;53:83-90.

86. Swaans MJ, Post MC, Rensing BJ, et al. Percutaneous left atrial appendage closure for stroke prevention in atrial fibrillation. Neth Heart J 2012;20:161-6.

87. Bai R, Horton RP, DI Biase L, et al. Intraprocedural and long-term incomplete occlusion of the left atrial appendage following placement of the WATCHMAN device: a single center experience. $J$ Cardiovasc Electrophysiol 2012;23:455-61.

88. Swaans MJ, Post MC, Rensing BJ, et al. Ablation for atrial fibrillation in combination with left atrial appendage closure: first results of a feasibility study. J Am Heart Assoc 2012;1:e002212.

89. Park JW, Bethencourt A, Sievert $\mathrm{H}$, et al. Left atrial appendage closure with Amplatzer cardiac plug in atrial fibrillation: initial European experience. Catheter Cardiovasc Interv 2011;77:700-6.

90. Lam YY, Yip GW, Yu CM, et al. Left atrial appendage closure with AMPLATZER cardiac plug for stroke prevention in atrial fibrillation: initial Asia-Pacific experience. Catheter Cardiovasc Interv 2012;79:794-800

91. Montenegro MJ, Quintella EF, Damonte A, et al. Percutaneous occlusion of left atrial appendage with the Amplatzer Cardiac PlugTM in atrial fibrillation. Arq Bras Cardiol 2012;98:143-50.

92. Danna P, Proietti R, Sagone A, et al. Does left atrial appendage closure with a cardiac plug system reduce the stroke risk in nonvalvular atrial fibrillation patients? A single-center case series. Pacing Clin Electrophysiol 2013;36:347-53.

93. Helsen $F$, Nuyens D, De Meester $P$, et al. Left atrial appendage occlusion: single center experience with PLAATO LAA Occlusion System() and AMPLATZER ${ }^{\mathrm{TM}}$ Cardiac Plug. J Cardiol 2013:62:44-9.

94. Nietlispach F, Gloekler S, Krause R, et al. Amplatzer left atrial appendage occlusion: single center 10-year experience. Catheter Cardiovasc Interv 2013;82:283-9.

95. Urena M, Rodés-Cabau J, Freixa X, et al. Percutaneous left atrial appendage closure with the AMPLATZER cardiac plug device in patients with nonvalvular atrial fibrillation and contraindications to anticoagulation therapy. J Am Coll Cardiol 2013;62:96-102.

96. Streb W, Szymala M, Kukulski T, et al. Percutaneous closure of the left atrial appendage using the Amplatzer Cardiac Plug in patients with atrial fibrillation: evaluation of safety and feasibility. Kardiol Pol 2013;71:8-16.

97. Meerkin D, Butnaru A, Dratva D, et al. Early safety of the Amplatzer Cardiac Plug ${ }^{\mathrm{TM}}$ for left atrial appendage occlusion. Int $\mathrm{J}$ Cardiol 2013 [Published online first]

98. Faustino A, Paiva L, Providência R, et al. Percutaneous closure of the left atrial appendage for prevention of thromboembolism in atrial fibrillation for patients with contraindication to or failure of oral anticoagulation: a single-center experience. Rev Port Cardiol 2013;32:461-71.

99. Reddy VY, Doshi SK, Sievert H, et al. Percutaneous left atrial appendage closure for stroke prophylaxis in patients with atrial fibrillation: 2.3-year follow-up of the PROTECT AF (Watchman Left Atrial Appendage System for Embolic Protection in Patients with Atrial Fibrillation) Trial. Circulation 2013;127:720-9

100. Hart RG, Pearce LA, Aguilar MI. Meta-analysis: anti-thrombotic therapy to prevent stroke in patients who have non-valvular atrial fibrillation. Ann Intern Med 2007;146:857-67. 